\title{
Growth, Characterization and Molecular Hyperpolarizabilities of Novel Nonlinear Optical Chalcone Crystals
}

\author{
A.N. PRABHU ${ }^{1}$, A. JAYARAMA ${ }^{2}$, V. UPADHYAYA ${ }^{1}$, K SUBRAHMANYA BHAT $^{3 *}$ \\ ${ }^{1}$ Department of Physics, Manipal Institute of Technology, Manipal University, \\ Manipal-576 104, India \\ ${ }^{2}$ Department of Physics, Mangalore Institute of Technology \& Engineering (MITE), \\ Moodabidri-574225, India \\ ${ }^{3}$ Department of Chemistry, Manipal Institute of Technology, \\ Manipal University-576104, India \\ sbkjrf@yahoo.co.in
}

Received 27 September 2013 / Accepted 8 November 2013

\begin{abstract}
A chalcone derivative, 1-(5-bromothiophen-2-yl)-3-(2,3-dimethoxyphenyl)prop-2-en-1one (BTDMP), has been synthesized and grown as a high-quality single crystal by the slow evaporation solution growth technique. The compound was characterized by FT-IR and NMR studies. The crystal has been subjected to single-crystal x-ray diffraction studies and cell parameters of the crystal were determined. The title compound crystallizes in monoclinic system with a centrosymmetric space group P21/c, with unit cell parameters $a=11.6473(6) \AA, b=8.5651(5) \AA$, $\mathrm{c}=14.4829(8) \AA, \alpha=90^{\circ}, \beta=99.853(2)^{\circ}, \gamma=90^{\circ}$ and $\mathrm{V}=1423.51(14) \AA^{3}$. The thermal stability of the crystal was determined from DSC curve. The grown crystals were characterized for their optical transmission and mechanical hardness. The potential of these crystals for NLO applications were studied using molecular hyperpolarizability calculations using MOPAC 2012.
\end{abstract}

Keywords: Chalcone derivative, Crystal structure, Crystal growth, Nonlinear optical materials

\section{Introduction}

Synthesis of organic compounds exhibiting nonlinear optical (NLO) properties have gained importance because of their applications in the area of optical communications, data storage, harmonic generators, frequency mixing and optical switching ${ }^{1,2}$. The benefit of using organic molecules over inorganic materials is that they can be designed to optimize the desired NLO property by having different donor and acceptor groups in the same molecules simply changing the substituents and functional groups on the starting reactants. Compounds are expected to have large values of molecular hyperpolarizability $(\beta)$ if they possess polarizable electrons, like $\pi$-electrons spread over a larger distances ${ }^{3,4}$. Chalcones possess extended 
conjugation and reported to exhibit good NLO property ${ }^{5-7}$. Synthesis of chalcones and related derivatives requires simple chemistry techniques when compared to other complex organic structures. Moreover, these types of compounds can easily be grown into bulk crystals using cheap organic solvents at ambient conditions. Most of the chalcone derivatives have good transparency and oxidative stability ${ }^{8,9}$. Recently, we found that presence of bromo substituent and sulfur atom especially in the form of thiophene ring is useful in getting good quality single crystals ${ }^{5,6}$. In continuation of our work on preparation and single crystal growth of newer chalcone derivatives, we describe the single-crystal growth and characterization of 1-(5-bromothiophen-2-yl)-3-(2,3-dimethoxyphenyl) prop-2en-1-one (BTDMP). The grown crystals were characterized by FTIR, NMR, UV- visible, DSC and single crystal x-ray diffraction studies. In order to study the influence of functional groups on molecular level nonlinear optical properties of these types of compounds, theoretical calculations were made using molecular orbital package (MOPAC 2012) program and compared with other chalcone derivatives reported in literature.

\section{Experimental}

The required chalcone derivatives can be synthesized by the Claisen-Schmidt condensation method as given in Figure $1^{10}$. The compound 1-(5-bromothiophen-2-yl)-3-(2,3dimethoxyphenyl)prop-2-en-1-one (BTDMP) was synthesized by dissolving a mixture of 2-acetyl-5-bromothiophene $(0.01 \mathrm{~mol})$ and 2,3 - dimethoxybenzaldehyde $(0.01 \mathrm{~mol})$ in methanol $(75 \mathrm{~mL})$. Sodium hydroxide $(7 \mathrm{~mL}, 20 \%)$ was then added drop wise to the solution and allowed to stir for $2 \mathrm{~h}$. The contents of the flask were poured into ice-cold water; the product was filtered, dried and re-crystallized twice using acetone.

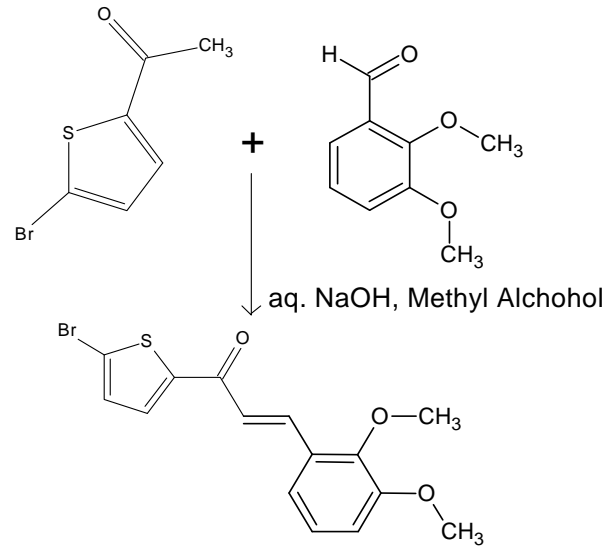

Figure 1. Synthesis of BTDMP

\section{Crystal growth and morphology}

Single crystals were grown in a beaker by slow evaporation solution growth technique at room temperature using acetone as a solvent. The saturated solution of the compound in pure acetone was prepared and undissolved impurities if any are removed by filtration. The beaker was covered with filter paper and allowed for slow evaporation. When tiny crystals were nucleated, they were allowed to grow to a larger dimension and then harvested. The laboratory grown crystals of BTDMP is shown in Figure 2a. The morphology of the crystal was simulated using single crystal XRD data and is presented in Figure 2b. The BTDMP crystals are pyramidal, with large habit face $\left(\begin{array}{lll}1 & 0 & 0\end{array}\right)$, distinct cleavage plane $\left(\begin{array}{lll}0 & 1 & 0\end{array}\right)$ and $\left(\begin{array}{lll}0 & 0 & 1\end{array}\right)$. 

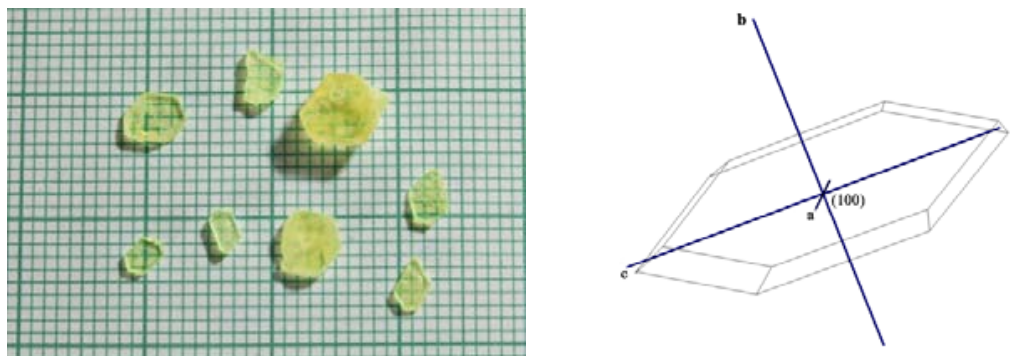

Figure 2. a) Single crystals of BTDMP and b) Indexed morphology of BTDMP

\section{Characterization}

\section{Surface structure of the crystals}

The most common habit of the BTDMP crystal grown in acetone is pyramidal. A uniform layered structural pattern was observed throughout the crystal. Scanning Electron Micrograph of the crystal BTDMP is shown in Figure 3. This shows step-like structure on the surface confirming the layered growth of the crystal.

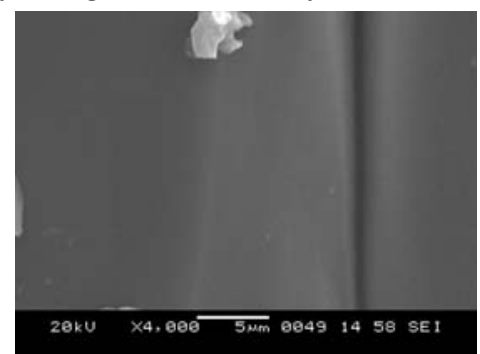

Figure 3. Scanning electron micrograph of BTDMP

\section{FT-IR and NMR spectral analysis}

The FT-IR analysis of BTDMP was carried out to investigate the presence of functional groups and their vibrational modes. The sample was prepared by mixing the compound with $\mathrm{KBr}$ pellet. The spectrum was recorded between 400 and $4000 \mathrm{~cm}^{-1}$ using a SHIMADZU8400 S FT-IR spectrometer. The IR spectrum of BTDMP exhibit strong absorption band at $1643 \mathrm{~cm}^{-1}$ due to presence of $\alpha, \beta$-unsaturated carbonyl $(-\mathrm{CH}=\mathrm{CH}-\mathrm{C}=\mathrm{O})$ stretching clearly confirming the formation of chalcone moiety. The absorption band corresponding to $\mathrm{C}-\mathrm{H}$ symmetric and asymmetric stretching of $\mathrm{OCH}_{3}$ group was observed in the wavenumber region of 2824 and $2939 \mathrm{~cm}^{-1}$ respectively. Further the absorption bands corresponding to aryl $\mathrm{C}-\mathrm{O}$ and alkyl $\mathrm{C}-\mathrm{O}$ stretching vibrations are observed at 1273 and $1072 \mathrm{~cm}^{-1}$. The strong absorption band corresponding to $\mathrm{C}=\mathrm{C}$ was observed at $1582 \mathrm{~cm}^{-1}$.

The NMR spectrum of the compound BTDMP show doublets at $\delta 8.106$ and 7.400 with a coupling constant of 16 corresponding to protons of $-\mathrm{CH}=\mathrm{CH}-$ group indicating their $E$-configuration. Other characteristic peaks observed in the spectrum are $\delta: 7.576(\mathrm{~d}, 1 \mathrm{H}, \mathrm{H}$ of thiophene ring), 7.1435 (d, 1H, H of thiophene ring), 7.091 (t, 1H, H of aromatic ring), 6.97825 (d, $2 \mathrm{H}, \mathrm{H}$ of aromatic ring), 7.2375 (d, 2H, $\mathrm{H}$ of aromatic ring), 3.891 (2 singlets, $6 \mathrm{H}, 2 \times \mathrm{OCH}_{3}$ ).

\section{Crystal structure determination}

1-(5-Bromothiophen-2-yl)-3-(2,3-dimethoxyphenyl)prop-2-en-1-one was subjected to single-crystal x-ray diffraction (XRD) using a Bruker axs kappa apex2 CCD Diffractometer. 
The details of the crystal data and refinement are given in Table 1. Compound BTDMP (Figure $4 \mathrm{a}$ ) is crystallized in monoclinic centrosymmetric space group $\mathrm{P} 2_{1} / \mathrm{c}$ with $\mathrm{Z}=4$. In the compound BTDMP, the bromothiophene and dimethoxyphenyl groups are linked by a prop-2-en-1-one group. The $\mathrm{C}=\mathrm{C}$ exhibits an E-conformation. The molecule is non-planar, with a dihedral angle of $19.09^{\circ}$ between the bromothiophene and dimethoxyphenyl rings. The methoxy group at position 3 is coplanar with the benzene ring to which it is attached, with a $\mathrm{C}-\mathrm{C}-\mathrm{O}-\mathrm{C}$ torsion angle of $4.28^{\circ}$. The methoxy group attached at position 2 of the benzene ring is in a $(+)$ synclinal conformation, as indicated by the $\mathrm{C}-\mathrm{C}-\mathrm{O}-\mathrm{C}$ torsion angle of $-109.9(2)^{\circ}$. In the crystal, two different $\mathrm{C}-\mathrm{H}$...O intermolecular interactions (Table 2) generate chains of molecules extending along the $b$ axis (Figure $4 b$ ).

Table 1. Crystal data and refinement of BTDMP [CCDC deposition No. 887292]

\begin{tabular}{|c|c|}
\hline DATA & BTDMP \\
\hline Molecular formula & $\mathrm{C}_{15} \mathrm{H}_{13} \mathrm{Br} \mathrm{O}_{3} \mathrm{~S}$ \\
\hline Formula weight & 353.22 \\
\hline Crystal System & Monoclinic \\
\hline Space group & $\mathrm{P} 2 / \mathrm{c}$ \\
\hline$a(\AA)$ & $11.6473(6)$ \\
\hline $\mathrm{b}(\AA)$ & $8.5651(5)$ \\
\hline$c(\AA)$ & $14.4829(8)$ \\
\hline Cell Angles (deg) & $\alpha=90, \beta=99.853(2), \gamma=90$ \\
\hline Volume $\left(\AA^{3}\right), \mathrm{Z}$ & $1423.51(14), 4$ \\
\hline Density $\left(\mathrm{Mg} \mathrm{m}^{-3}\right)$ & 1.648 \\
\hline Crystal color, habit & transparent, pyramidal \\
\hline Crystal size $\left(\mathrm{mm}^{3}\right)$ & $0.5 \times 0.40 \times 0.30$ \\
\hline Radiation used, $\lambda(\AA)$ & $\operatorname{Mo~K}_{\alpha}, \lambda=0.71073$ \\
\hline Absorption coefficient, $\mu\left(\mathrm{mm}^{-1}\right)$ & 3.038 \\
\hline $\mathrm{T}(\mathrm{K})$ & $296(2)$ \\
\hline Reflections collected / unique & $21632 / 3486$ \\
\hline$\theta$ range $(\mathrm{deg})$ & $2.77-28.24$ \\
\hline $\mathrm{R}_{\text {int }}$ & 0.0799 \\
\hline $\mathrm{F}(000)$ & 712 \\
\hline Goodness-of-fit on $\mathrm{F}^{2}$ & 0.999 \\
\hline Final $\mathrm{R}$ indices $[\mathrm{I}>2 \sigma(\mathrm{I})]$ & $\mathrm{R}_{1}=0.0401, \mathrm{wR}^{2}=0.1061$ \\
\hline $\mathrm{R}$ indices (all data) & $\mathrm{R}_{1}=0.0557, \mathrm{wR}^{2}=0.1149$ \\
\hline Largest diff. peak and hole $\left(\mathrm{e} / \AA^{3}\right)$ & 0.599 and -0.544 \\
\hline Least square weight $\mathrm{P}=\left(\mathrm{F}_{\mathrm{o}}^{2}+2 \mathrm{~F}_{\mathrm{c}}^{2}\right) / 3$ & $\mathrm{w}=1 /\left[\sigma^{2}\left(\mathrm{~F}_{0}^{2}\right)+(0.0674 \mathrm{P})^{2}+0.1731 \mathrm{P}\right]$ \\
\hline
\end{tabular}

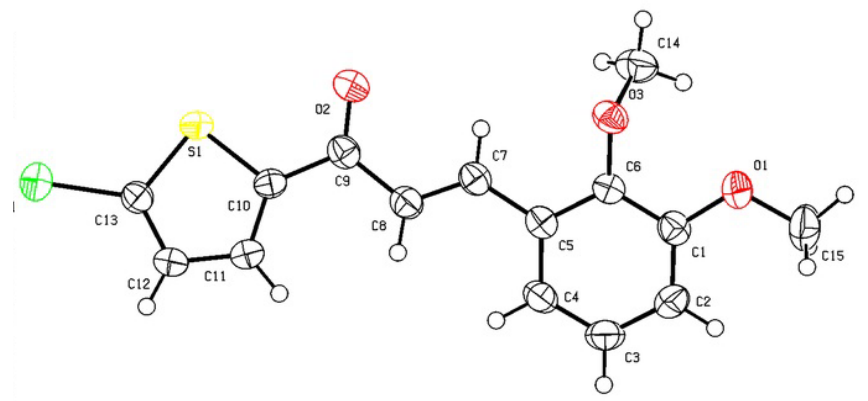




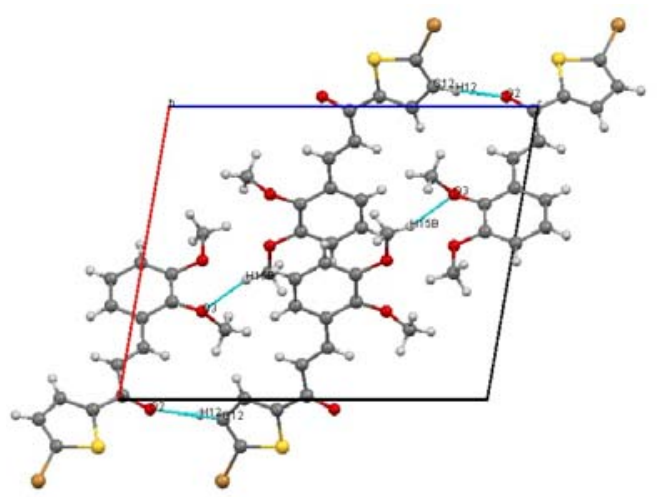

Figure 4. The molecular structure of BTDMP, showing 50\% probability ellipsoids (a), and unit cell packing of the title compound showing intermolecular interactions with dotted lines (b)H atoms not involved in hydrogen bonding have been excluded for clarity.

Table 2. Geometries of intermolecular Interactions from structural analysis of BTDMP

\begin{tabular}{llllll}
\hline Interactions & $\mathrm{X}-\mathrm{H}(\AA)$ & $\mathrm{H}---\mathrm{A}(\AA)$ & $\mathrm{X}---\mathrm{A}(\AA)$ & $\mathrm{X}-\mathrm{H}---\mathrm{A}\left(^{\circ}\right)$ & Symmetry \\
\hline $\mathrm{C} 13-\mathrm{C} 12---\mathrm{H} 14 \mathrm{C}$ & $1.342(3)$ & $2.802(3)$ & $3.276(3)$ & $98.2(2)$ & $2-\mathrm{x}, 1-\mathrm{y}, 1-\mathrm{z}$ \\
$\mathrm{C} 12-\mathrm{H} 12---\mathrm{O} 2$ & $0.930(2)$ & $2.492(2)$ & $3.201(3)$ & $133.1(2)$ & $\mathrm{x}, 1.5-\mathrm{y},-1 / 2+\mathrm{z}$ \\
$\mathrm{C} 9-\mathrm{O} 2---\mathrm{H} 12$ & $1.218(3)$ & $2.492(2)$ & $3.442(2)$ & $133.2(2)$ & $\mathrm{x}, 1.5-\mathrm{y}, 1 / 2+\mathrm{z}$ \\
$\mathrm{C} 9-\mathrm{O} 2---\mathrm{C} 12$ & $1.218(3)$ & $3.201(3)$ & $4.248(3)$ & $144.2(2)$ & $\mathrm{x}, 1.5-\mathrm{y}, 1 / 2+\mathrm{z}$ \\
$\mathrm{C} 14-\mathrm{H} 14 \mathrm{C}---\mathrm{C} 12$ & $0.959(4)$ & $2.802(3)$ & $3.496(4)$ & $129.9(2)$ & $2-\mathrm{x}, 1-\mathrm{y}, 1-\mathrm{z}$ \\
$\mathrm{C} 6-\mathrm{O} 3---\mathrm{H} 15 \mathrm{~B}$ & $1.373(3)$ & $2.548(2)$ & $3.628(2)$ & $133.1(1)$ & $1-\mathrm{x}, 1 / 2+\mathrm{y}, 1.5-\mathrm{z}$ \\
$\mathrm{C} 15-\mathrm{H} 15 \mathrm{~B}---\mathrm{O} 3$ & $0.961(3)$ & $2.548(2)$ & $3.418(4)$ & $150.7(2)$ & $1-\mathrm{x},-1 / 2+\mathrm{y}, 1.5-\mathrm{z}$ \\
$\mathrm{C} 13-\mathrm{C} 12---\mathrm{O} 2$ & $1.342(3)$ & $3.201(3)$ & $4.257(3)$ & $135.0(2)$ & $\mathrm{x}, 1.5-\mathrm{y},-1 / 2+\mathrm{z}$ \\
\hline
\end{tabular}

\section{Mechanical properties of the crystals}

\section{Density measurement}

Crystal purity was determined by measuring the density of the crystal using specific gravity bottle at ambient temperature $\left(27^{\circ} \mathrm{C}\right)$. The average value of density was $1.654 \mathrm{~g} / \mathrm{cm}^{3}$ and is comparable with value calculated from single crystal $\mathrm{x}$-ray diffraction data $\left(1.648 \mathrm{~g} / \mathrm{cm}^{3}\right)$. The bulk density measured for the laboratory-grown single crystal is slightly different from the density value calculated from single crystal XRD data which may be due to the lattice distortions due to presence of point defects in the crystal.

\section{Micro hardness studies}

The mechanical hardness is one of the important factors that decide the applicability of the material and also in selecting the processing conditions for bulk crystals ${ }^{11}$. The mechanical strength of the crystal was determined using Vicker's micro hardness tester (CLEMEX digital micro hardness tester "MATSUZAWA, Japan). Vickers microhardness number (VHN) was calculated using the relation

$$
\mathrm{VHN}=\frac{1.8544 \mathrm{P}}{\mathrm{d}^{2}} \mathrm{~kg} / \mathrm{mm}^{2}
$$

Where $\mathrm{P}$ is the applied load in $\mathrm{kg}$ and $\mathrm{d}$ is the mean diagonal length of the indenter impression in millimeter. Load dependence of microhardness was carried out for the loads $3 \mathrm{~g}, 5 \mathrm{~g}, 10 \mathrm{~g}, 25 \mathrm{~g}$ and $50 \mathrm{~g}$. Crack initiation and materials chipping become significant 
beyond $50 \mathrm{~g}$ of the applied load. Figure 5 indicates the variation of hardness as a function of applied load. It is observed that, the value of hardness decreases with increasing load and with further increase in load the hardness becomes independent of load, which indicates normal indentation size effect ${ }^{12}$.

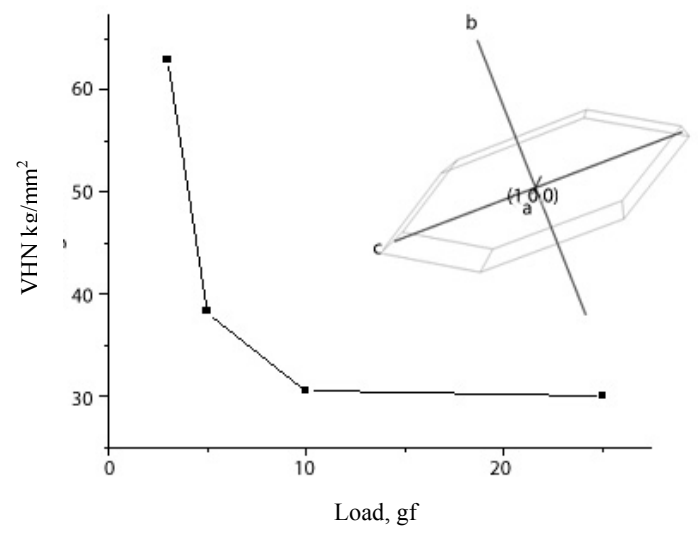

Figure 5. Load dependence of Vicker's hardness of BTDMP

\section{Optical Studies}

\section{UV-Visible spectrum}

The UV-Visible absorption spectrum of the compound was recorded using a UV-1601PC UV-visible spectrophotometer in the wavelength range of $200-800 \mathrm{~nm}$ and is shown in Figure 6. It is clear that the BTDMP has a lower optical cutoff at $415 \mathrm{~nm}$ and is transparent in the entire visible region. The crystal has strong absorption band in the UV-region, due to $\mathrm{n}-\pi^{*}$ transition due to the presence of aromatic ring and $\mathrm{C}=\mathrm{O}$ group. The absence of the absorption in the visible region is the desirable characteristic for the compounds used in NLO applications ${ }^{13}$.

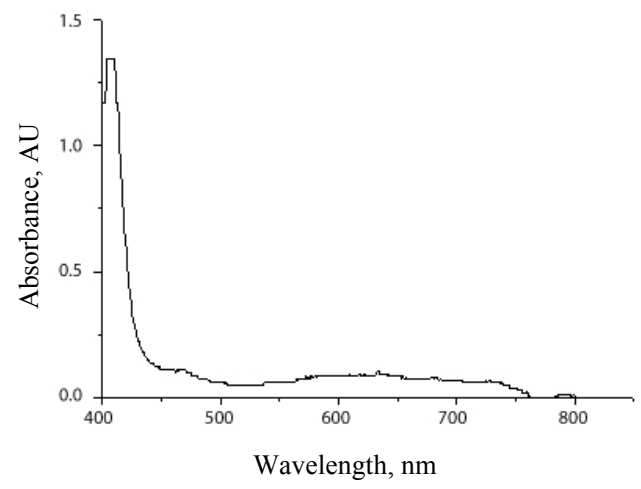

Figure 6. Optical absorption spectrum of BTDMP

\section{Refractive index measurement}

The values of the refractive indices of the crystal, for wavelengths 632.8 and $543.5 \mathrm{~nm}$ were measured using Brewster's angle method ${ }^{14}$ and found to be 1.558 and 1.570 respectively. BTDMP would be a worthwhile material to be considered for optical application because of its lower refractive indices in comparison to inorganic materials. 


\section{Molecular design and structure - NLO property relationship}

Among the four synthesized chalcone derivatives only BTNP crystallizes in noncentrosymmetric space group and shows high SHG efficiency (ref Table 3). The SHG efficiency of the crystal depends on the orientation of the molecules in the crystal lattice. Three chalcone derivatives (CTTMP, CTDMP and BTDMP) possess D- $\pi$-A- $\pi$-D type structure and remaining one (BTNP) has D- $\pi$-A- $\pi$-A (an effective D- $\pi-A$ ) type structure. In D- $\pi-A-\pi-D$ type chalcones, the charge transfer is from ends to the centre of the molecule where as in D- $\pi$-A type chalcones the charge transfer is from end to the end of the molecule. The synthesized chalcone derivatives such as CTTMP, CTDMP, BTDMP and BTNP has thiophene ring linked to benzene ring through a carbonyl group. The $\mathrm{Br}$, methoxy $\left(\mathrm{OCH}_{3}\right)$ groups in these molecules act as electron donor groups and $\mathrm{NO}_{2}$, carbonyl group $(\mathrm{C}=\mathrm{O})$ acts as an electron withdrawing group. Chlorine can act both as electron donor as well as electron acceptor. The electron donating strength of the substituted groups vary as $\mathrm{Br}<\mathrm{Cl}<\mathrm{OCH}_{3}$ and the electron accepting strength varies as $\mathrm{C}=\mathrm{O}<\mathrm{Cl}<\mathrm{NO}_{2}$. The donor / acceptor group substituted on the thiophene and phenyl group greatly alters the molecular hyperpolarizability of the chalcone derivatives.

Effective charge transfer depends on the molecular planarity ${ }^{16}$ and the twist in molecule may result in an ineffective charge transfer leading to decreased NLO response. The planarity of the molecule increases the delocalization of electrons and therefore enhances the hyperpolarizabilities. It is clear that the charge transfer is more effective in BTNP chalcone derivative due to the better planarity of the molecule.

The crystal classes $1,2, \mathrm{~m}$ and $\mathrm{mm} 2$ were shown to be favorable cases for optimized SHG activity ${ }^{17}$. It may be interesting to note that the commercially available NLO crystals of considerable interest like $\mathrm{MNA}^{18,19}, \mathrm{MAP}^{20}, \mathrm{NPP}^{21}$ crystallize in the favored point group $\mathrm{m}$, 2,2 and $\mathrm{mm} 2$, respectively. The compound BTNP crystallize in the point group 1, which is favorable for nonlinear optical (NLO) interaction. In the molecular structure of BTNP crystal, the para position of thiophene ring consists of a $\mathrm{Br}$ atom. $\mathrm{Br}$ acts as electron donor and $\mathrm{NO}_{2}$ as strong electron acceptor group. BTNP containing $\mathrm{Br}$ and $\mathrm{NO}_{2}$ at the ends and an electron acceptor carbonyl group $(\mathrm{C}=\mathrm{O})$ at the middle forms a $\mathrm{D}-\pi-\mathrm{A}$ system, where effective charge transfer takes place from donor end to the acceptor end of the molecule. The SHG efficiency of the crystal BTNP is about four times that of urea ${ }^{5}$. The hydrogen bond interaction such as $\mathrm{C}-\mathrm{H} \cdots \mathrm{O}$ and $\mathrm{C}-\mathrm{H} \cdots \mathrm{S}$ in BTNP helps to extend the intra molecular charge transfer and expect to contribute to the observed high SHG. Further the shape of the BTNP chalcone derivative can be considered as $\Lambda$-shape, which helps to align the molecule in a parallel head-to-tail alignment in the crystal packing. Such molecular alignment usually exhibits high SHG efficiency ${ }^{16}$.

Chalcones are cross-conjugated molecules, and the carbonyl $(\mathrm{C}=\mathrm{O})$ group in this system breaks the conjugation system into two independent parts to have increased molecular hyperpolarizability. The unit cells of $\mathrm{CTTMP}^{22}$ and CTDMP $^{23}$ consists of 4 molecules. A weak $\mathrm{C}-\mathrm{H} \cdots \mathrm{O}$ hydrogen bond helps, molecules to pack in a head-to-tail fashion along the crystallographic $c$-axis and b-axis respectively. As a result, the dipole moment of each molecule adds to establish molecular hyperpolarizability in these crystals. Even though the $\mathrm{C}-\mathrm{H} \cdots \mathrm{O}$ interactions are weak in this crystal, they may play a significant role in the excited state to extend the molecular charge transfer through intermolecular interaction into the supramolecular realm.

The structure - NLO property studies with static molecular first hyperpolarizability $\left(\beta_{0}\right)$, first hyperpolarizability $(\beta)$ and second hyperpolarizability $\left(\gamma_{\mathrm{o}}\right)$ of all the molecules were computed using molecular orbital package (MOPAC) 2012, a semiempherical computer program ${ }^{15}$. 
To optimize the molecular geometry of these molecules the Eigenvector Following (EF) geometry optimizer was used which is a default geometry optimizer in MOPAC2012 program. To compute molecular static and frequency dependent first hyperpolarizability of these chalcone, the Time Dependent Hartree-Fock theory ${ }^{15}$ was used.

The geometry of molecules obtained from the single crystal XRD study was used as input to MOPAC 2012 program. The molecular hyperpolarizabilities of all the compounds are listed in Table 3. The variation of $\beta$ values among the compounds suggests that the substitution of two $\mathrm{OCH}_{3}$ group at phenyl moiety is optimum to increase the $\beta$ values of chalcone derivatives and further increase in number of methoxy group results in decreased value of $\beta$. To obtain a chalcone derivative with high $\beta$ value it is better to add an strong electron acceptor at the phenyl group $\left(\mathrm{NO}_{2}\right)$ and replace electron withdrawing $\mathrm{Cl}$ with $\mathrm{Br}$ at the thiophene group. It is observed from the Table 3 that only SHG active compound shows high $\beta$ values.

The hyperpolarizability values for CTTMP, CTDMP, BTDMP and BTNP tabulated in Table 3 clearly suggests that the substitution of more than two $\mathrm{OCH}_{3}$ groups, results in a decrease of hyperpolarizability values in these molecules. This decrease is attributed to the steric hindrance caused by the multiple bulky methoxy groups present at the adjacent positions which affect the intramolecular charge transfer. It is clear from the solid state structure reported for trimethoxy substituted chalcones ${ }^{24-27}$ that the methoxy group attached at the para position of CTTMP is pushed out of the plane due to the presence of two or more adjacent bulky methoxy groups in the phenylene group. Among the three centrosymmetric chalcone derivatives (CTTMP, CTDMP and BTDMP) BTDMP is having high molecular hyperpolarizability due to the delocalization of $\pi$ electrons.

Table 3. Calculated molecular hyperpolarizability of chalcone derivatives

\begin{tabular}{|c|c|c|c|c|c|c|c|c|}
\hline Compound & $\mathrm{R}_{1}$ & $\mathrm{R}_{2}$ & $\mathrm{R}_{3}$ & $\mathrm{R}_{4}$ & $\mathrm{R}_{5}$ & $\begin{array}{l}\text { Static first } \\
\text { hyperpolari- } \\
\text { zability }\left(\beta_{\mathrm{o}}\right) \\
\left(1 \times 10^{-28}\right. \\
\text { esu) }\end{array}$ & $\begin{array}{c}\text { first } \\
\text { hyperpolari } \\
\text { zability }(\beta) \\
\left(1 \times 10^{-26} \mathrm{esu}\right) \\
\text { at } 1064 \mathrm{~nm}\end{array}$ & $\begin{array}{c}\text { Static } \\
\text { second } \\
\text { hyperpolari- } \\
\text { zability }\left(\gamma_{\mathrm{o}}\right) \\
\left(1 \times 10^{-32} \mathrm{esu}\right)\end{array}$ \\
\hline СТTMP & $\mathrm{Cl}$ & $\mathrm{OCH}_{3}$ & $\mathrm{H}$ & $\mathrm{OCH}_{3}$ & $\mathrm{OCH}_{3}$ & 12.9 & 9.51 & 6.54 \\
\hline CTDMP & $\mathrm{Cl}$ & $\mathrm{OCH}_{3}$ & $\mathrm{OCH}_{3}$ & $\mathrm{H}$ & $\mathrm{H}$ & 13.7 & 13.3 & 7.09 \\
\hline BTDMP & $\mathrm{Br}$ & $\mathrm{OCH}_{3}$ & $\mathrm{OCH}_{3}$ & $\mathrm{H}$ & $\mathrm{H}$ & 17.1 & 106 & 10.2 \\
\hline BTNP & $\mathrm{Br}$ & $\mathrm{H}$ & $\mathrm{H}$ & $\mathrm{NO}_{2}$ & $\mathrm{H}$ & 9.69 & 405 & 4.75 \\
\hline
\end{tabular}

In the molecular structure of BTDMP, the para position of thiophene ring consists of a $\mathrm{Br}$ atom. $\mathrm{Br}$ acts as electron donating group. The $\mathrm{OCH}_{3}$ group is also a donor group. The electron donating strength of the $\mathrm{OCH}_{3}$ group is greater than $\mathrm{Br}$. The BTDMP molecule containing $\mathrm{Br}$ and two $\mathrm{OCH}_{3}$ groups at the ends and an electron acceptor carbonyl $(\mathrm{C}=\mathrm{O})$ group at the middle forms a donor- $\pi$-acceptor- $\pi$-donor (D- $\pi$-A- $\pi$-D) system, where charge transfer takes place from the donor ends to the acceptor at the middle of the molecule. 


\section{Thermal studies}

The thermal property of BTDMP was studied in the powder form by recording the differential scanning colorimeter (DSC) response curve in the temperature range $30{ }^{\circ} \mathrm{C}$ to $250{ }^{\circ} \mathrm{C}$, at a rate of $10{ }^{\circ} \mathrm{C} / \mathrm{min}$, in nitrogen atmosphere using SHIMADZU differential scanning calorimeter (DSC-60). The DSC plot shown in Figure 7, shows an endothermic peak at $118.30{ }^{\circ} \mathrm{C}$, which corresponds to the melting point of BTDMP. The reasonably good melting point of the crystal makes it worthwhile for exploring in device fabrications.

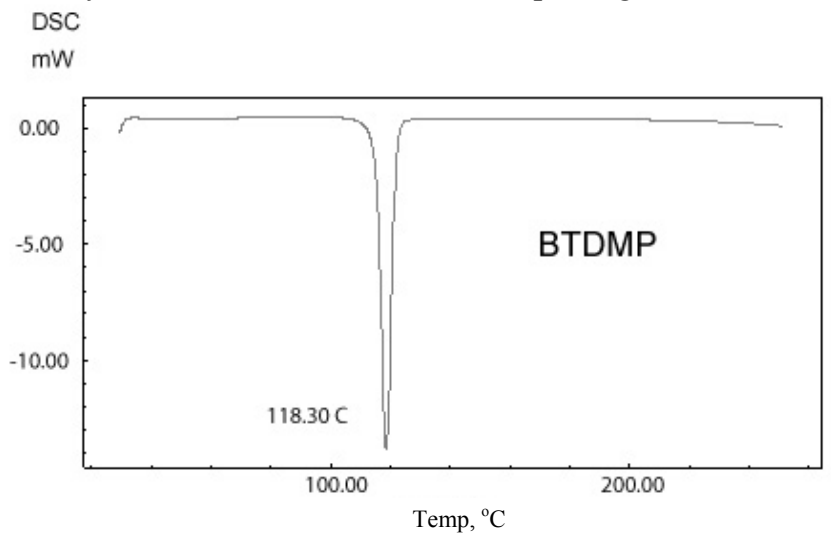

Figure 7. DSC curve of BTDMP

\section{Conclusion}

Single crystals of the chalcone BTDMP were grown by slow evaporation technique. Scanning electron microscope image confirms step-like growth of the crystal. The hyperpolarizability values of all compounds clearly suggest that the substitution of more than two $\mathrm{OCH}_{3}$ groups, results in a decrease of molecular static first hyperpolarizabilities $\left(\beta_{\mathrm{o}}\right)$, first hyperpolarizabilities $(\beta)$ and static second hyperpolarizabilities $\left(\gamma_{\mathrm{o}}\right)$ values in this molecules. The decrease in hyperpolarizability values is attributed to the steric hindrance caused by the multiple bulky methoxy groups present at the adjacent positions which affect the intramolecular charge transfer. Among the three centrosymmetric chalcone derivatives, MOPAC calculation shows that BTDMP is having high molecular hyperpolarizability. The good transparency, thermal stability and high molecular hyperpolarizability values indicate that it is a promising candidate for NLO applications.

\section{Acknowledgement}

Authors are thankful to Ajith Kumar, Department of Chemistry, Manipal Institute of Technology, Manipal University, India for recording FTIR and UV spectrum. Authors also thank G. Umesh and Manjunatha KB, NITK Surathkal for providing Z-Scan Experimental facilities.

\section{References}

1. Chemla D S and Zyss J, Nonlinear Optical Properties of Organic molecules and Crystals, Academic Press, New York, 1987.

2. Prasad P N and Williams D J, Introduction to Nonlinear Optical Effects in Organic Molecules and Polymers, Wiley, New York, 1991.

3. Oudar J L and Chemla D S, J Chem Phys., 1977, 66(6), 2664; DOI:10.1063/1.434213 
4. Oudar J L, J Chem Phys., 1977, 67, 446; DOI:10.1063/1.434888

5. Prabhu A N, Jayarama A, Bhat K S and Upadhyaya V, J Mol Str., 2013, 1031, 79-84; 10.1016/j.molstruc.2012.06.057

6. Prabhu A N, Jayarama A, Upadhyaya V and Bhat K S, Mat Chem Phy., 2013, 138(1), 179-185; DOI:10.1016/j.matchemphys.2012.11.041

7. Ganapayya B, Jayarama A and Dharamaprakash S M, Mol Cryst Liq Cryst., 2013, 571(1), 87-98; DOI:10.1080/15421406.2012.722832

8. Shubhalaxmi, Hahne S, Jayarama A and Bhat K S, Chem Sci Trans., 2013, 2(3), 829-834; DOI:10.7598/cst2013.438

9. Shubhalaxmi, Hahne S, Zschille C, Jayarama A and Bhat K S, Chem Sci Trans., 2013, 2(3), 841-846; DOI:10.7598/cst2013.532

10. Dhar D N, The Chemistry of Chalcones and Related Compounds, Wiley, New York, 1981.

11. Munn R W and Ironside C N, Principles and Applications of Nonlinear Optical Materials Chapman \& Hall, London, 1993.

12. D'silva E D, Rao D N, Reji P, Ray B J, Rajnikant and Dharmaprakash S M, J Phys Chem Solids, 2011, 72(6), 824-830; DOI:10.1016/j.jpcs.2011.04.003

13. Kalsi P S, Spectroscopy of Organic Compounds, Wiley Eastern Ltd, New Delhi, 1995.

14. Grossman C H and Garito A F, Mol Cryst Liq Cryst., 1989, 168(1), 255-267; DOI:10.1080/00268948908045976

15. Stewart J J P, MOPAC 2012, Stewart Computational Chemistry. Colorado Springs, Co, USA, http://OpenMOPAC.net2012

16. Zyss J, (Eds)., Molecular Nonlinear Optics: Materials, Physics and Devices. Academic Press: New York, 1994.

17. Zyss J and Oudar J L, Phys Rev., 1982, A26, 2028.

18. Levine B F, Bethea C G, Thurmond C D, Lynch R T and Bernstein J L, J Appl Phys., 1979, 50(4), 2523; DOI:10.1063/1.326248

19. Lipscomb G F, Garito A F and Narang R S, J Chem Phys., 1981, 75(3), 1509; DOI:10.1063/1.442157

20. Ouder J L and Hierle R, J Appl Phys., 1977, 48(7), 2699; DOI:10.1063/1.324120

21. Zyss J, Nicoud J F and Coquillay M, J Chem Phys., 1984, 81(9), 4160; DOI:10.1063/1.448134

22. Prabhu A N, Jayarama A, Row T N G and Upadhyaya V, Acta Cryst., 2011, E67 2086; DOI:10.1107/S1600536811028236

23. Prabhu A N, Jayarama A, Sankolli R, Row T N G and Upadhyaya V, Acta Cryst., 2011, E67, 2665; DOI:10.1107/S1600536811037135

24. Ravindra H J, Dharmaprakash S M and Harrison W T A, Acta Cryst., 2007, E63, o2877o2879; DOI:10.1107/S1600536807021551

25. Ng S L, Razak I A, Fun H K, Patil P S and Dharmaprakash S M, Acta Cryst., 2006, E62, o4650-04652; DOI:10.1107/S1600536806037275

26. Ng S L, Patil P S, Razak I A, Fun H K and Dharmaprakash S M, Acta Cryst., 2006, E62, o1228-o1230; DOI:10.1107/S1600536806007239

27. Harrison W T A, Ravindra H J, Kumar M R S and Dharmaprakash S M, Acta Cryst., 2007, E63, o3970; DOI:10.1107/S1600536807041840 